\title{
Endovascular strategies for post-dissection aortic aneurysm (PDAA)
}

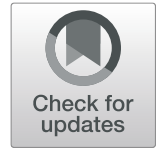

Zhaoxiang Zeng ${ }^{\dagger}$, Yuxi Zhao ${ }^{\dagger}$, Mingwei $\mathrm{Wu}^{\dagger}$, Xianhao Bao, Tao Li, Jiaxuan Feng ${ }^{*}$, Rui Feng ${ }^{*}$ and Zaiping Jing ${ }^{*}$

\begin{abstract}
Residual patent false lumen (FL) after type B aortic dissection (TBAD) repair is independently associated with poor long-term survival. Open surgery and endovascular repair result in good clinical outcomes in patients with AD. However, both treatments focus on proximal dissection but not distal dissection. About $13.4-62.5 \%$ of these patients present with different degrees of distal aneurysmal dilatation after primary repair. Although open surgery is the first-choice treatment for post-dissection aortic aneurysm (PDAA), there is a need for high technical demand since open surgery is associated with high mortality and morbidity. As a treatment strategy with minimal invasion, endovascular repair shows early benefits and low morbidity. For PDAA, the narrow true lumen (TL), rigid initial flap and branch arteries originating from FL have increased difficulties in operation. The aim of endovascular treatment is to promote $\mathrm{FL}$ thrombosis and aortic remodeling. Endovascular repair includes intervention from FL and TL sides. TL intervention techniques (parallel stent-graft, branched and fenestrated stent-graft among others) have been proven to be safe and effective in PDAA. Other FL intervention techniques that have been used in selected patients include FL embolization and candy-plug techniques. This article introduces available endovascular techniques and their outcomes for the treatment of PDAA.
\end{abstract}

Keywords: TEVAR, Post-dissection aortic aneurysm, False lumen, Endovascular repair , Candy-plug

\section{Introduction}

Thoracic endovascular aortic repair (TEVAR) is widely used for type $\mathrm{B}$ aortic dissection (TBAD) due to the availability of advanced endovascular techniques and acceptable outcomes. Currently, the treatment strategy of TEVAR is to enhance aortic remodeling as it excludes proximal tear, reduces blood pressure and induces thrombogenesis in the false lumen (FL) [1]. However, backflow from distal entry tears maintains perfusion to $\mathrm{FL}$, inducing aneurysm formation. About $13.4-62.5 \%$ of patients show different degree of distal aneurysmal dilatation after TEVAR $[2,3]$. The presence of distal residual tears affects the long-term survival of patients [4].

\footnotetext{
*Correspondence: fengjiaxuan01@163.com; 320165900@qq.com; xueguaky@163.com

${ }^{\dagger}$ Zhaoxiang Zeng, Yuxi Zhao and Mingwei Wu contributed equally to this work.

Department of Vascular Surgery, Changhai Hospital, Navy Medical University, 168 Changhai Road, Shanghai 200433, People's Republic of China
}

Although open surgery is still the first-choice treatment for post-dissection aortic aneurysm (PDAA), it still requires high technical demands and is also associated with increased mortality and morbidity [5]. Endovascular strategies regarded as less invasive treatment with good early outcomes are suitable for patients unable to tolerate open surgery. The indications for endovascular treatment are similar to those for open surgery, such as aneurysms $>5.5 \mathrm{~cm}$ in diameter or those with rapidly expand $>1 \mathrm{~cm} /$ year and aneurysm-related symptoms (refractory pain, malperfusion and compression complications, et al.). Nowadays, available endovascular methods are increasingly used in the treatment of PDAA in high-volume centers. Several electronic databases (including EMBASE and MEDLINE) were searched to identify potential studies. And searching strategies included "TEVAR","post-dissection aortic aneurysm", "chronic aortic dissection", "endovascular repair" and 
"stent-graft". According to the relevant results, we can divide the techniques into interventions from FL side and from True lumen (TL) side. This article aims to discuss different endovascular strategies and outcomes for PDAA.

\section{Trans-TL repair TEVAR}

The concept of TEVAR is excluding proximal entry tears to induce positive aortic remodeling. As to PDAA, TEVAR extends the tubular stent-grafts above the level of celiac axis. This can exclude tears above the celiac trunk and reduce flow and pressure of the FL. However, distal residual tears may affect long-term survival. Studies have demonstrated that aortic remodeling is mainly concentrated in the covered thoracic aortic segment after TEVAR [6]. A report by Mani $\mathrm{K}$ et al. indicated that complete FL thrombosis after TEVAR for chronic AD occurred in one-third of patients. But for most cases, positive aortic remodeling and complete thrombosis were frequently limited to the thoracic aortic segment [7]. The latest meta-analysis from Boufi $M$ showed that when chronic AD is treated by TEVAR, the 1-year and 3 -year follow-up survival rates were similar, which was $91 \%$, and aortic-related mortality was $3.2 \%$. The reintervention rate was $20.2 \%$, and the risk of aortic rupture was 3\% [8]. In cases of PDAA extent to visceral segment or abdominal aorta, this method is confined to exclude all tears. A survey from our center reported that the average number of residual tears was $6.10 \pm 3.16$. Among them, the numbers in thoracic descending aorta, visceral segment, infra-renal abdominal aorta and iliac artery were $1.07 \pm 1.59,1.53 \pm 1.27,2.30 \pm 1.41$ and $1.20 \pm 0.80$, respectively [2]. The most drawback of traditional TEAV
$\mathrm{R}$ is that it is limited to exclude the entry tears in thoracic descending aorta.

The importance of the distal landing zone for TEVAR in the treatment of aortic dissection has been highlighted in previous studies. The "cheese wire" technique describes that using a hydrophyllic guidewire to unzip initial flap creates a landing zone for endovascular treatment. The method was first used by Watkinson in a patient with severe iliac artery occlusion [9]. Later on, Iwakoshi $\mathrm{S}$ et al used this method to treat three patients with chronic $\mathrm{AD}$, and there was one case for type III endoleak and another for renal artery occlusion which required re-intervention [10]. However, significant risks with this technique persisted, for example, intimal flap occlusion of visceral arteries. Some scholars have also explored the use of endovascular scissors in AD [11, 12]. Endovascular scissors have been developed by Alomran F for complicated acute TBAD with severe malperfusion (Fig. 1). The technique was performed in three patients and no complications occurred at 2-year follow-up [13]. Although these techniques can create a complete distal landing zone, available information is case series. Besides, the safety and generality of these techniques remain a problem to explored.

\section{The evolution of PETTICOAT (provisional extension to induce complete attachment) technique}

The PETTICOAT concept involved a standard TEVAR to exclude proximal tears and distal uncovered stentgraft to expand distal TL associated with stabilization of dissecting initial flap. Therefore, this method was more effective in non-chronic dissection, because initial flap can be expanded. It evolved from the earliest prototype of a simple bare stent-graft to a composite device design.
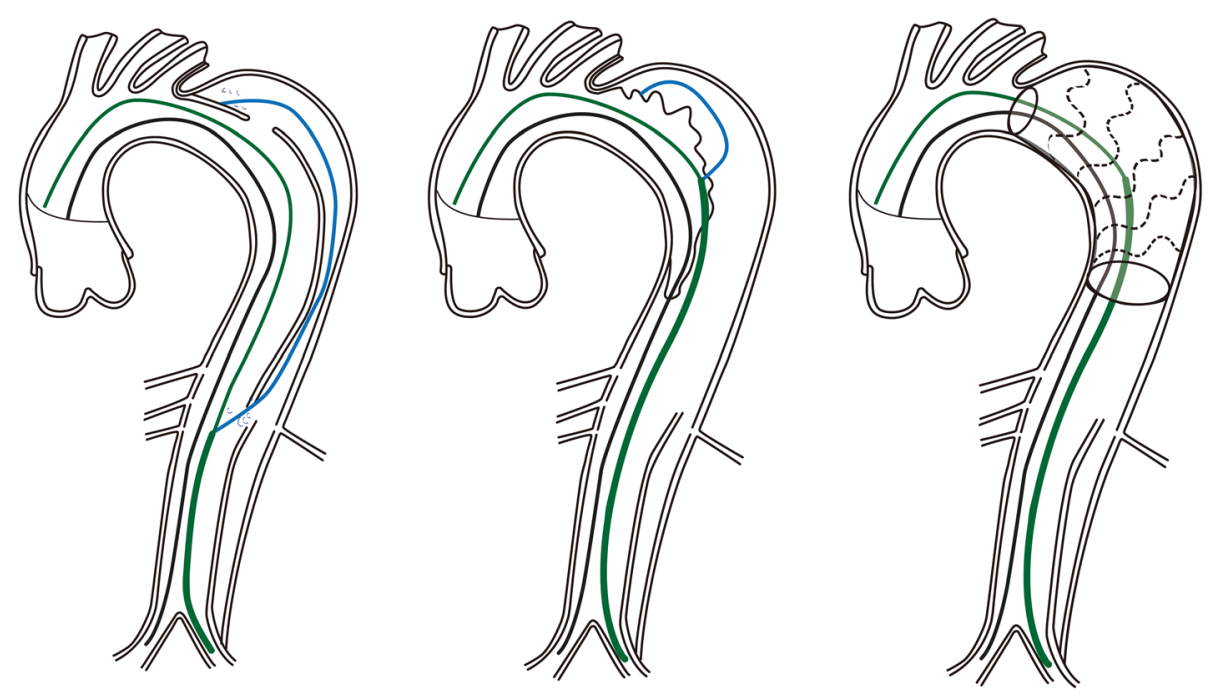

Fig. 1 Endovascular scissors technique 
The prototype of PETTICOAT technique dates back to 2003 (Fig. 2). The first report on the use of selfexpanding bare stents for the treatment visceral arteries malperfusion was by Ito $\mathrm{N}$ et al [14]. In 2006, this technique was officially named by Nienaber CA [15]. Twelve patients demonstrated distal TL collapse and a perfused FL after sealing of the proximal tears were treated. A stent-graft was placed for distal extension for the stentgraft previously implanted to obliterate sustained abdominal FL flow and pressurization. After one-year follow-up, 11 patients had complete thoracic thrombosis with benign aortic remodeling. One patient without FL thrombosis died at 11 months due to aortic rupture. Later, Lars Kock introduced DEEB PETTICOAT (Distal
Extended Branched PETTICOAT) technique which worked in combination with FL arteries construction to treat 26 patients with complicated TBAD (unpublished data, presented at VEITH Symposium 2017). There was no aortic related deaths or branched arteries occlusion within 28.7 months after surgery. Besides, Kazimierczak A tried the extended petticoat strategy in TBAD [16]. This strategy provided diffuse mechanical aorto-iliac support and led to complications necessitating reintervention when treating extensive TBAD. Based on the concept of PETTICOAT, Lombardi JV et al. proposed a composite device design to treat complicated type B aortic dissection [17]. The device comprised a pathology-specific device comprising a proximal stent

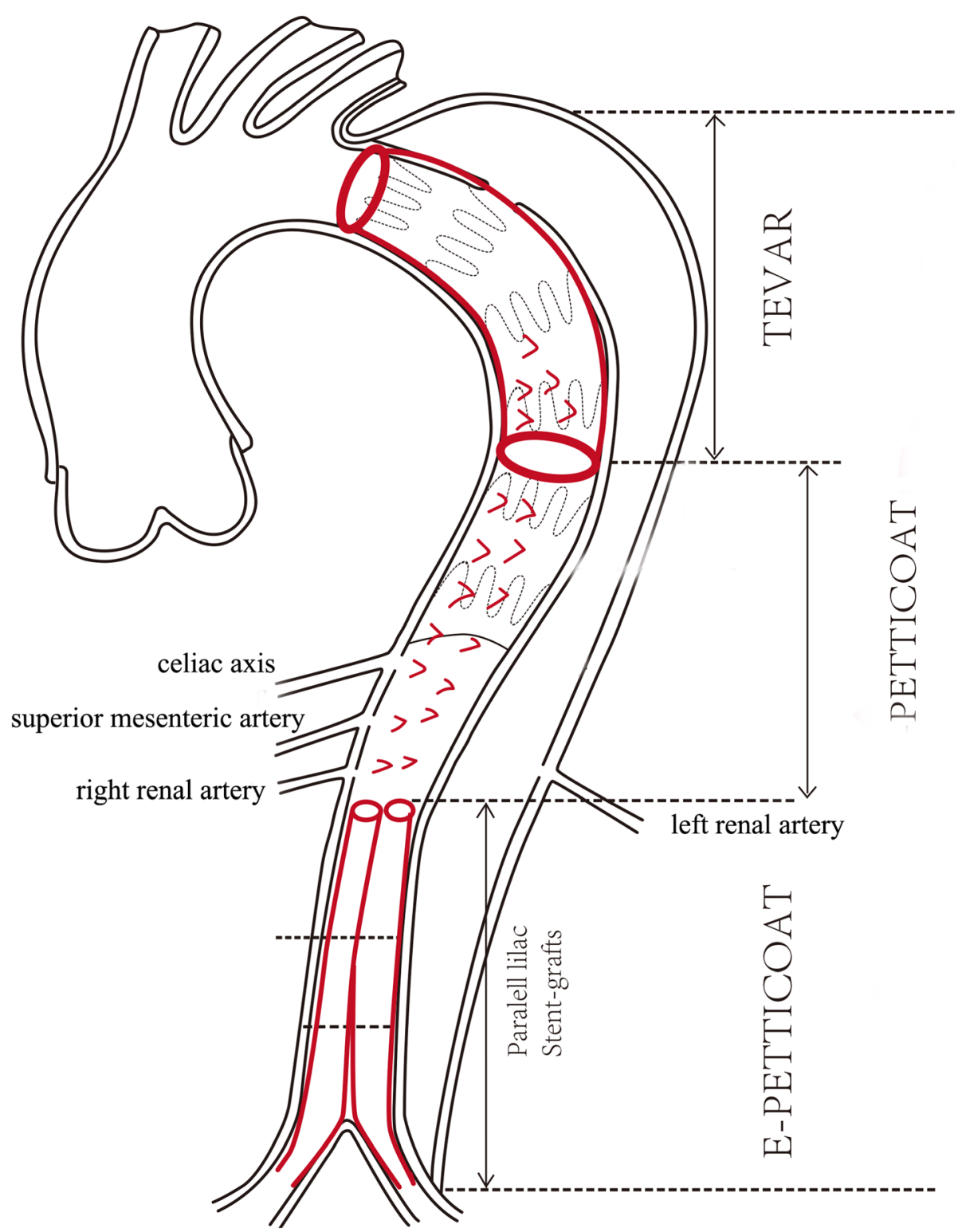

Fig. 2 PETTICOAT technique 
graft with barbs and a distal bare stainless steel stent. The STABLE I trial recruited 86 patients (55 in acute phase and 31 in nonacute phase). The 30-day mortality rate was 5.5\% (3 of 55) for acute and 3.2\% (1 of 31) for nonacute. There was an overall increase in true lumen diameter, and false lumen shrinkage was observed both in acute and nonacute phase at the level of thoracoabdominal aortas. At 5 years, freedom from intervention was $65.5 \% \pm 7.5 \%$ for acute and $71.2 \% \pm 9.0 \%$ for nonacute patients. However, some scholars were worried about the risks associated with aneurysm formation since the technique expanded the TL leaving distal tears untreated $[18,19]$. More robust evidence was needed to demonstrate the safety and effectiveness of the technique.

\section{STABILISE (stent-assisted balloon-induced intimal} disruption and relamination in aortic dissection repair) and Knickbocker technique

Different from PETTICOATS technique, STABILISE and Knickbocker technique worked by deliberately disrupting initial flap to create a single lumen. After operation, the distal backflow was blocked. In 2014, Hofferberth SC et al. proposed the STABILISE technique derived from PETTICOAT [20]. Eleven patients underwent proximal descending aortic endograft combined with stent-assisted balloon of the thoracoabdominal aorta to treat complicated AD. There were no intraprocedural complications recorded. However, a patient died within 1 month, although complete FL obliteration was achieved in nine patients. The group of Faure EM has also reported experience in treating TBAD whereby in a series of 41 patients, no intra-procedural complications were recorded. Exactly 15 branch arteries originating from FL were constructed. The 30-day death, stroke and paralysis/visceral ischemia rates were $2,0,5$, and $2 \%$ respectively. The patency of visceral branched arteries was 93\%. Eight patients required secondary intervention. No aortic related deaths occurred. Complete FL obliteration and aortic remodeling was realized in all patients at the thoracoabdominal level [21]. In addition, the technique was successfully applied in patients with Marfan syndrome [22]. All patients had complete aortic remodeling of the treated aortic segment. Knickbocker, another technique for intimal flap disruption, was described by Kölbel T in 2014 [23]. With this technique, an oversized thoracic tubular endograft was placed in the narrow TL to induce intimal flap disruption, which occluded distal backflow into FL. It has been successfully used in three patients with PDAA, and the FL aneurysm remained thrombosed with no mortality recorded during follow up (Fig. 3). Both STABILISE and Knickbocker technique were not widely accepted due to the potential risk of aortic rupture.

\section{Parallel stent-graft technique (PST, Fig. 4)}

PST is widely used to treat complex aortic lesions [24, 25]. Because of the low requirement for stent-grafts, the technique owes unique advantages in dealing with emergent cases. The technique was applied by Liu J et al. to treat 21 post-dissection thoracoabdominal aneurysms [26]. Four cases of type I endoleaks occurred after repair, which disappeared spontaneously within 1 month. Neither spinal cord ischemia nor organ malperfusion were observed. During an average follow-up of 16 months, two cases of type II endoleaks occurred. Nineteen FL achieved complete thrombosis, and the total aortic diameter decreased from $57.3 \pm 8.4$ to $55.3 \pm 7.4 \mathrm{~mm}$.

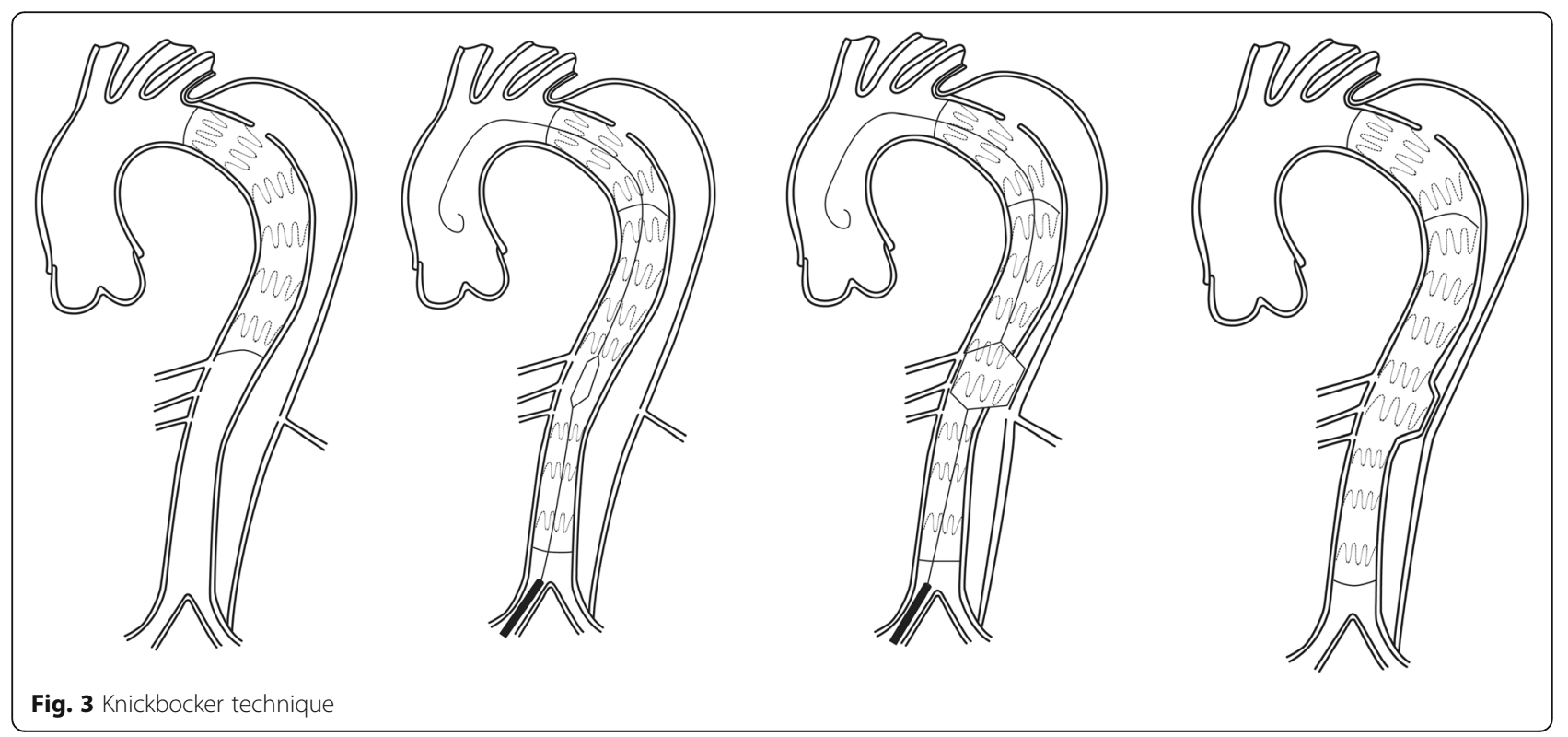



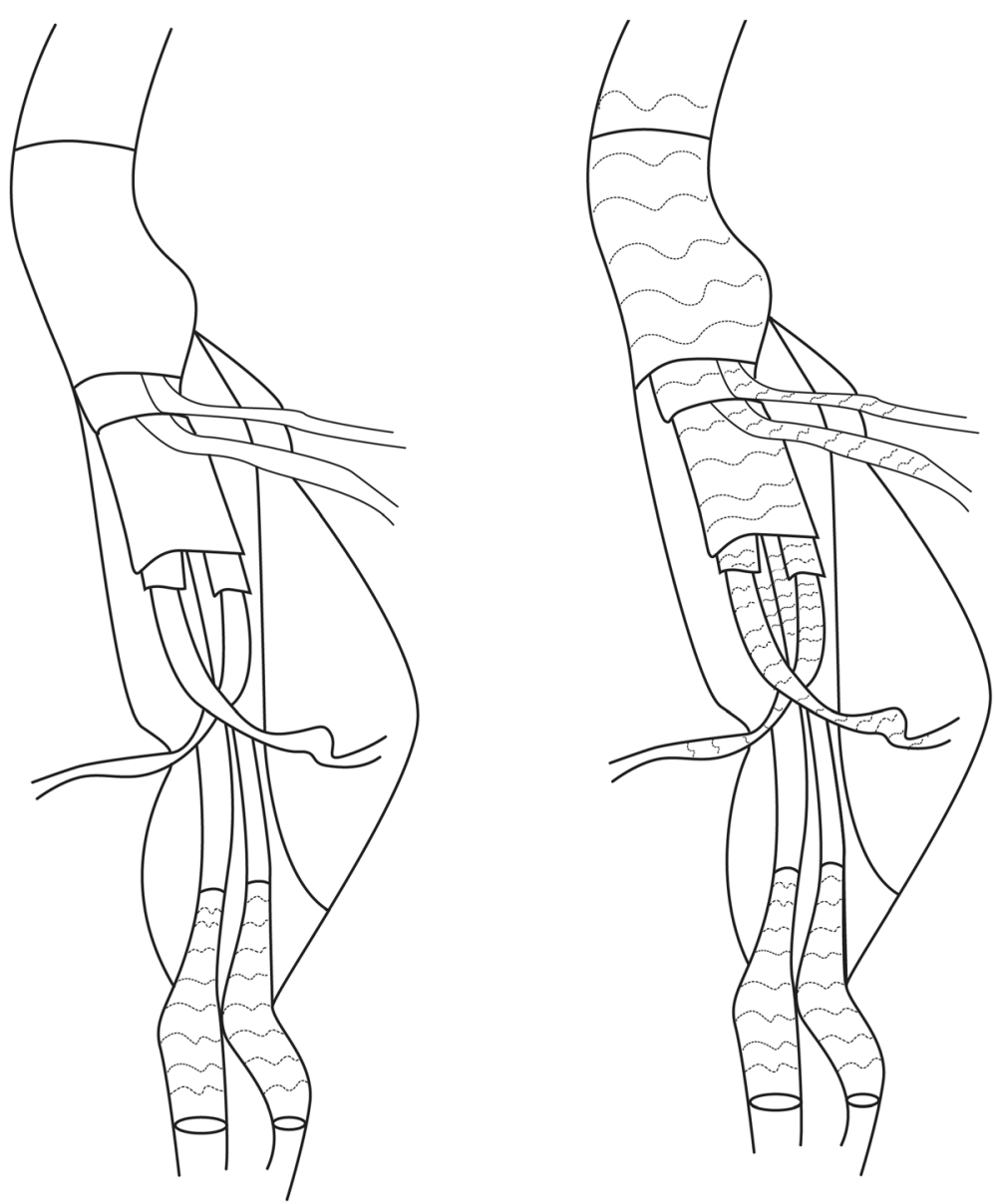

Fig. 4 Parallel stent-graft technique

Three $(4.3 \%, 3 / 70)$ target branch arteries occluded. To avoid the risk of endoleak, sufficient overlap between stents was recommended. How to "maintain the balance between sufficient overlap and cost" remained to be explained. Furthermore, although the results of the study were encouraging, the long-term patency of visceral branches remained a concern.

\section{Branched and fenestrated stent-graft (Fig. 5)}

Branched and fenestrated stent-graft is considered a safe and effective way of treating thoracoabdominal aortic aneurysms (TAAA) $[27,28]$. In cases where TAAA has appropriate anatomical conditions, branched and fenestrated stent-graft is taken as the first-line treatment option [29]. Unlike degenerative TAAA, the anatomies of PDAA have some drawbacks. The narrow TL, branch arteries that arise from FL and stiff initial flap limit the effect of endovascular treatment. Upon the expansion of narrow TL, the anatomical characteristics of branch arteries change accordingly. The fenestrated stent-graft can adapt to the relatively narrow TL, but superselection of branch arteries places great technical difficulties on the operators. The existence of small cuff to branched stent-graft is important in reconstructing visceral branched arteries but requires a spacious room. Mayo Clinic applied auxiliary preloaded guidewires to treat TAAA on 83 patients with TAAA or pararenal aortic aneurysm. The technical success rate was $99.7 \%$ on average operation time of $160 \mathrm{~min}, 30$-day mortality was recorded as $0 \%$ [30]. The result revealed that this technique could facilitate visceral branched arterial reconstruction and reduce the difficulty of operation. The concept of inner branched stent-graft provides an option for visceral arteries unsuitable for branched and fenestrated stent-graft. Findings from Katsargyris A et al. reported their early experience in treating complex aortic lesions with inner branched stent-graft. The 30-motality rate was $3.1 \%(1 / 32)$, and 1-year overall survival rate was $80 \%$. During the follow-up period, four renal inner branches occluded in three patients. The patency of inner branched stent-graft at 1 year was $91.9 \pm 4.5 \%$, and re-intervention at 1 -year rate was $11.6 \% \pm 8.9 \%$ [31]. Another vexing problem was reconstruction of visceral artery, especially those totally originated from FL. 

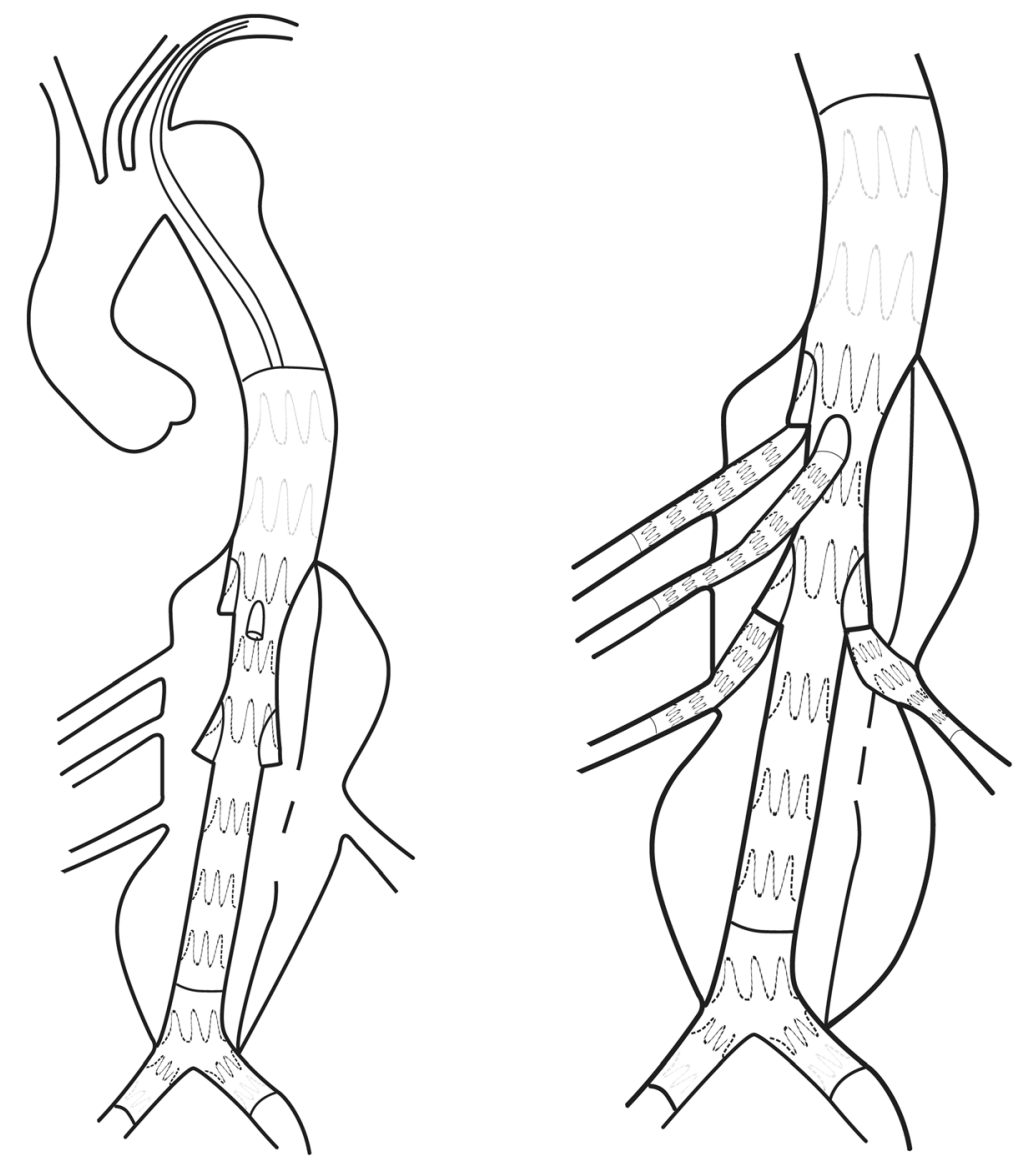

Fig. 5 Branched and fenestrated stent-graft technique

Catheterization usually was placed from the TL, through the tear in the visceral segment and FL, into the target artery. Some scholars performed an in-situ fenestration to create a new approach to target vessels if there was no re-entry tear at the level of target vessels.

\section{Multilayer bare stents/multilayer flow modulator (MBS/ MFM)}

A lot of controversies exist with the treatment of aortic lesions using MBS/MFM. MBS/MFM device induces thrombus formation as it changes the flow status in the FL. It sufficiently restores flow perfusion, decompress the FL, eliminate local flow recirculation, and reduces wall shear stress distribution. Moreover, the device restores flow to organ perfusion despite its effect on TL patency [32]. In a study, 38 patients having chronic AD were treated using the device. All-causes survival was 85.3\% within 1-year follow up. No aortic ruptures or aortic-related deaths were observed. Aortic morphologic remodeling is reflected by a reduction in longitudinal length of the dissected aorta and FL volume [33]. In our experience, the technique was addressed to six cases with degenerative thoracoabdominal aortic aneurysms
[34]. During a mean follow-up of 14 months, four patients realized aneurysm shrinkage, and two aneurysms maintained stabilization. Notably, the presence of MBS/ MFM increased the operation difficulty if patients need re-intervention. The coil had to get through stent shunts to visceral artery, and the manoeuvrability of the stent was greatly reduced.

\section{Trans-FL repair}

\section{FL embolization}

FL embolization prevents backflow at the level of the distal descending aorta. Intervention from the FL side prevents excessive coverage of the aorta and reduces the risk of spinal cord ischemia. Currently, there are no devices designed for FL embolism. Coils, onyx glue and vascular plug are commonly used. In 2003, Loubert MC named the technique "the cork in the bottleneck" and successfully rescued two patients with PDAA [35]. Hofferberth introduced the concept of aortic FL thrombosis induction through embolotherapy (AFTER). Ten patients (four acute type $\mathrm{A} A \mathrm{AD}$, three acute TBAD and three chronic TBAD) received staged aortic repair. Averagely within 7 months after initial repair, directed 
embolization was performed. Nine out of ten patients realized aneurysm shrinkage or stability. One patient with chronic AD died 4 months after post-embolization [36]. Another embolization device, iliac occluders, has also been reported [37, 38]. Kim TH compared the outcomes of patients who underwent TEVAR with/without FL procedure. No statistically significant difference in the extent of aortic remodeling (TL expansion and FL regression) was observed between two groups. The cumulative proportion of thoracic FL thrombosis was high in the group of TEVAR with FL procedure [39]. In our opinion, FL embolization was considered to be a complementary and auxiliary therapeutic measure, especially in the cases with great FL in the distal aorta.

\section{Candy plug (Fig. 6a)}

In addressing the problem with large false lumen diameters, Kölbel $\mathrm{T}$ created an extra-large vascular plug to occlude FL in chronic AD. A $42 \mathrm{~mm}$ diameter Zenith thoracic stent-graft was modified into a "wrapped candy" and deployed in the FL above the celiac axis level. The first-generation was sutured in the middle to create a central opening for locally available vascular plug devices [40]. In 2017, Rohlffs F reported the early outcomes of this technique in 18 patients. The clinical success rate was $94 \%$. There were no intraprocedural complications. Complete distal FL occlusion was present in 15 patients [41]. The use of new generation Candy-Plug II in the treatment of 14 chronic dissections had been presented by Eleshra A. The new generation Candy-Plug II with a self-closing channel construction obviates additional placement of a plug. Its technical success was $100 \%$ with immediate FL flow completely blocked in 12 patients. Two patients received re-intervention. Eight of the nine patients presented aortic remodeling, while one aneurysm sac was stable [42]. Relevant anatomy for the use of the Candy-Plug Technique includes access to FL at distal aorta and sufficient extension of FL above the celiac axis for device deployment. By contrast, we deployed stent-grafts in FL to exclude tears from the side of FL in visceral segment and used TL stent-graft to exclude the tears and expand TL in infra-renal segment. The distal end of FL stent-graft was extended to abdominal segment (Fig. 6b). Eleven patients with PDAA were successfully treated from FL side. All patients had a stable or shrinking trans-aortic diameter in the abdominal aorta. There was no aortic related death during the follow-up. Wu IH et al used the iliac limb instead of suture to restrict the diameter in the middle section of stent-graft [43]. Another improvement of this technique had also been reported [44].

\section{Other intervention methods from $\mathrm{FL}$}

This procedure is only limited to some cases with severely narrow TL. In 2016, Bertoglio deployed branched stent-grafts in the TL and FL to exclude a PDAA. The right renal artery was reconstructed through the proximal TL. The branched stent-graft in the FL restored the

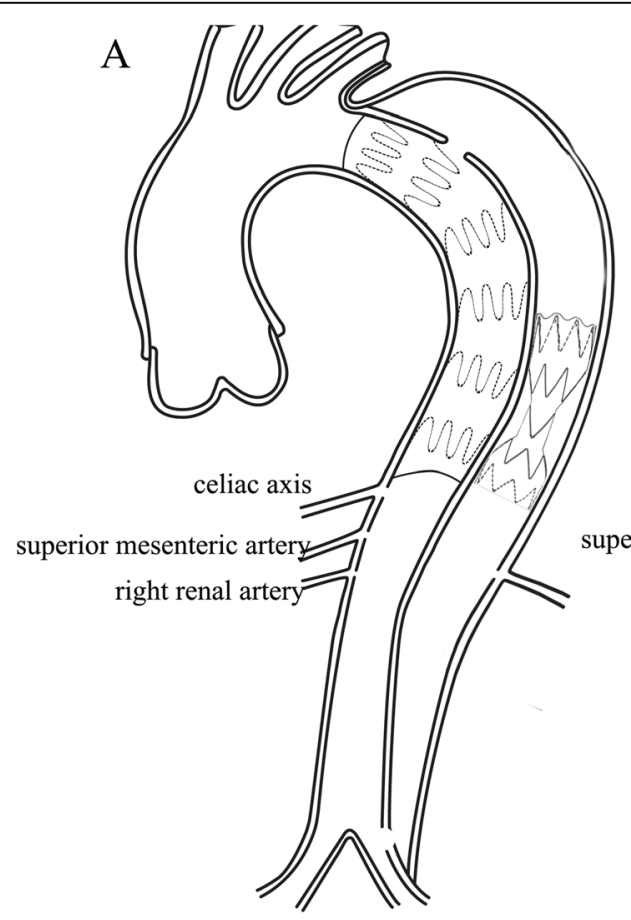

B

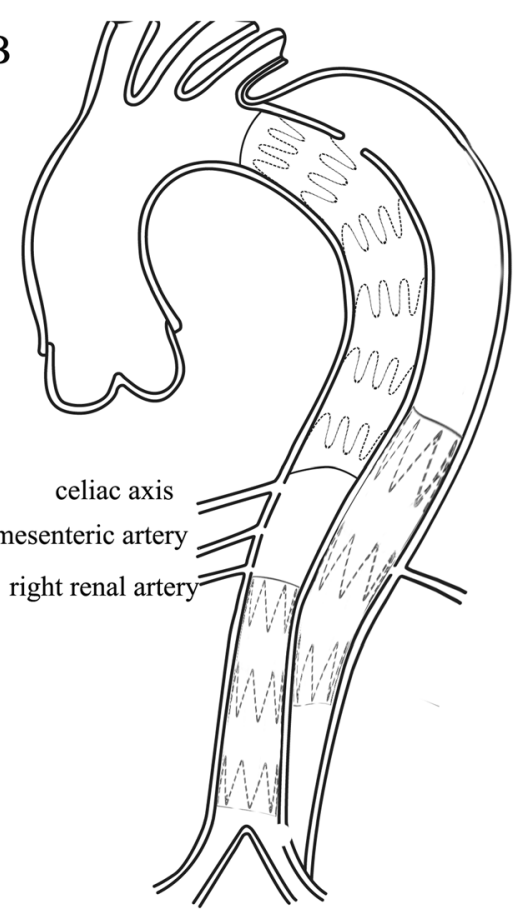

Fig. $\mathbf{6}$ a Candy-plug technique; $\mathbf{b}$ "Double splint" technique 
Table 1 Summary of treatment strategies of PDAA

\begin{tabular}{|c|c|c|}
\hline & Advantages & Disadvantages \\
\hline \multicolumn{3}{|l|}{ Trans-TL Repair } \\
\hline TEVAR & $\begin{array}{l}\text {-Exclude tears above the celiac trunk } \\
\text { - Reduce flow and pressure of the FL }\end{array}$ & $\begin{array}{l}\text {-unable to exclude the entry tears in visceral artery segment of } \\
\text { abdominal aorta } \\
\text {-Distal residual tears may result in negative remodeling }\end{array}$ \\
\hline PETTICOAT & $\begin{array}{l}\text {-Expand distal TL } \\
\text {-Stabilization of dissecting initial flap } \\
\text {-Effective in non-chronic AD }\end{array}$ & $\begin{array}{l}\text {-The risk aneurysm formation } \\
\text {-Distal residual tears untreated }\end{array}$ \\
\hline STABILISE and Knickbocker & $\begin{array}{l}\text {-Create a single lumen to block distal } \\
\text { backflow }\end{array}$ & -The risk of aortic rupture \\
\hline Parallel stent-graft technique & $\begin{array}{l}\text { - Flexible combination } \\
\text {-Suitable for a variety of anatomy } \\
\text {-Suitable for emergency and selective } \\
\text { operation }\end{array}$ & $\begin{array}{l}\text {-Endoleak } \\
\text { - Recurrent aortic dissection } \\
\text {-Chimney stent occlusion } \\
\text {-Cost expensive }\end{array}$ \\
\hline $\begin{array}{l}\text { Branched and fenestrated } \\
\text { stent-graft }\end{array}$ & $\begin{array}{l}\text { - Suitable for uncomplicated anatomical } \\
\text { conditions } \\
\text {-Widely used in PDAA }\end{array}$ & $\begin{array}{l}\text { - Difficult in TL stenosis cases } \\
\text {-Difficult in reconstruction of visceral artery totally originated from } \\
\text { FL. }\end{array}$ \\
\hline MBS/MFM & $\begin{array}{l}\text { - Restores flow perfusion } \\
\text {-Decompress the FL }\end{array}$ & $\begin{array}{l}\text {-Visceral artery ischemia } \\
\text { - Difficulty in re-intervention }\end{array}$ \\
\hline \multicolumn{3}{|l|}{ Trans-FL Repair } \\
\hline FL embolization & $\begin{array}{l}\text {-Avoid excessive coverage of the TL of aorta } \\
\text { - Reduces the risk of spinal cord ischemia } \\
\text {-A complementary and auxiliary therapeutic } \\
\text { measure }\end{array}$ & -No special devices for FL embolism \\
\hline Candy plug & $\begin{array}{l}\text {-Promote the thoracic aorta segment aortic } \\
\text { remodeling }\end{array}$ & $\begin{array}{l}\text {-No effect for abdominal FL } \\
\text {-The potential risk of aortic rupture }\end{array}$ \\
\hline
\end{tabular}

PDAA Post-dissection aortic aneurysm, TL True lumen, TEVAR Thoracic endovascular aortic repair, FL False lumen, PETTICOAT Provisional extension to induce complete attachment, $A D$ Aortic dissection, STABILISE Stent-assisted balloon-induced intimal disruption and relamination in aortic dissection repair, MBS/MFM Multilayer bare stents/multilayer flow modulator

other visceral arteries. Follow-up results after 6 months from operation showed that all visceral arteries were patent [45]. A report presented by Guo W et al. indicated successful total EVAR via retrograde reconstruction of the left renal artery from the false lumen [46]. On the one hand, these reports offered a new treatment idea: reconstruction of visceral arteries from FL could be applied in selected cases. On the other hand, these could not be considered as a standard of case.

\section{Conclusion}

Stent-graft treatment in chronic type B dissection differs from acute type B pathology based on increased stiffness of the dissecting lamella and a continued FL expansion. Stent-graft deployment in chronic dissection does not necessarily focus on the expansion of TL, but aims to depressurize the FL by promoting progressive thrombosis. Although there are a series of methods to treat patients with PDAA, available clinic reports are limited to a few high-volume centers. Considering the advantages and disadvantages of each technology (Table 1),treatment recommendations are not only based on levels of evidence but the cost-effect analyses. Additionally, the complex anatomy of PDAA indicates that all endovascular strategies should be used with caution and strict indication. Personally, for those with TL highly stenosis, the future direction may reconstruct the visceral arteries in combination with the TL and the FL, so as to obtain the best hemodynamics and long-term prognosis. More prospective and randomized clinical trials are warranted to provide solid evidence on this topic.

\section{Abbreviations}

PDAA: Post-dissection aortic aneurysm; AD: Aortic dissection; TBAD: Type B aortic dissection; TEVAR: Thoracic endovascular aortic repair; TL: True lumen; FL: False lumen

\section{Acknowledgments \\ Not applicable.}

\section{Authors' contributions}

FR provided the concept and ideas behind this work. ZZ and ZY collected data and drafted the initial manuscript. BX and LT provided all the figures. The manuscript was written by ZZ, ZY and WM, supervised by FJ. FR and JZ provided supervision of all aspects of the project. All authors read and approved the final manuscript.

\section{Funding}

This study was funded by National Natural Science Foundation of China [81770476].

\section{Availability of data and materials Not applicable.}

Ethics approval and consent to participate Not applicable.

\section{Consent for publication}

Yes 


\section{Competing interests}

The authors declare that they have no competing interests.

Received: 21 May 2020 Accepted: 22 September 2020 Published online: 01 October 2020

\section{References}

1. Riambau V, Böckler D, Brunkwall J, et al. Editor's choice - Management of Descending Thoracic Aorta Diseases: clinical practice guidelines of the European Society for Vascular Surgery (ESVS). Eur J Vasc Endovasc Surg. 2017:53:4-52.

2. Zhang $S$, Chen Y, Zhang Y, et al. Should the distal tears of aortic dissection be treated? The risk of distal tears after proximal repair of aortic dissection. Int J Cardiol. 2018;261:162-6.

3. Fattori $\mathrm{R}$, Montgomery $\mathrm{D}$, Lovato $\mathrm{L}$, et al. Survival after endovascular therapy in patients with type $B$ aortic dissection: a report from the international registry of acute aortic dissection (IRAD). JACC Cardiovasc Interv. 2013;6: 876-82.

4. Song SW, Kim TH, Lim SH, et al. Prognostic factors for aorta remodeling after thoracic endovascular aortic repair of complicated chronic DeBakey IIIb aneurysms. J Thorac Cardiovasc Surg. 2014;148:925-32 933.e1; discussion 932-3.

5. Estrera AL, Sandhu H, Afifi RO, et al. Open repair of chronic complicated type B aortic dissection using the open distal technique. Ann Cardiothorac Surg. 2014;3:375-84.

6. Kang WC, Greenberg RK, Mastracci TM, et al. Endovascular repair of complicated chronic distal aortic dissections: intermediate outcomes and complications. J Thorac Cardiovasc Surg. 2011;142:1074-83.

7. Mani K, Clough RE, Lyons OT, et al. Predictors of outcome after endovascular repair for chronic type B dissection. Eur J Vasc Endovasc Surg. 2012:43:386-91.

8. Boufi M, Patterson BO, Loundou AD, et al. Endovascular versus open repair for chronic type B dissection treatment: a meta-analysis. Ann Thorac Surg. 2019;107:1559-70

9. Watkinson AF. A novel "cheese wire" technique for stent positioning following difficult iliac artery subintimal dissection and aortic re-entry. Cardiovasc Intervent Radiol. 2009:32:781-4.

10. Iwakoshi S, Watkins CA, Ogawa Y, et al. "Cheese Wire" Fenestration of Dissection Intimal Flap to Facilitate Thoracic Endovascular Aortic Repair in Chronic Dissection. J Vasc Interv Radiol. 2020;31:150-154.e2

11. Berguer R, Parodi JC, Schlicht M, et al. Experimental and clinical evidence supporting septectomy in the primary treatment of acute type B thoracic aortic dissection. Ann Vasc Surg. 2015;29:167-73.

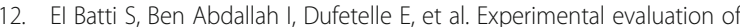
endovascular fenestration scissors in an ovine model of aortic dissection. Eur J Vasc Endovasc Surg. 2018:56:373-80.

13. Alomran F, Alsac JM. Distal endovascular fenestration INslde thoracic exclusion: the DEFINITE technique for complicated acute type B aortic dissections. Eur J Vasc Endovasc Surg. 2017;53:103

14. Ito N, Tsunoda T, Nakamura M, et al. Percutaneous bare Z-stent implantation as an alternative to surgery for acute aortic dissection with visceral ischemia. Catheter Cardiovasc Interv. 2003;58:95-100.

15. Nienaber CA, Kische S, Zeller $T$, et al. Provisional extension to induce complete attachment after stent-graft placement in type B aortic dissection: the PETTICOAT concept. J Endovasc Ther. 2006:13:738-46.

16. Kazimierczak A, Rynio P. Extended petticoat strategy in type B aortic dissection. Eur J Vasc Endovasc Surg. 2019;57:302.

17. Lombardi JV, Cambria RP, Nienaber CA, et al. Five-year results from the Study of Thoracic Aortic Type B Dissection Using Endoluminal Repair (STABLE I) study of endovascular treatment of complicated type B aortic dissection using a composite device design. J Vasc Surg. 2019;70:1072-1081.e2.

18. Sobocinski J, Lombardi JV, Dias NV, et al. Volume analysis of true and false lumens in acute complicated type B aortic dissections after thoracic endovascular aortic repair with stent grafts alone or with a composite device design. J Vasc Surg. 2016:63:1216-24.

19. Melissano G, Bertoglio L, Rinaldi E, et al. Volume changes in aortic true and false lumen after the "PETTICOAT" procedure for type B aortic dissection. J Vasc Surg. 2012;55:641-51.

20. Hofferberth SC, Nixon IK, Boston RC, et al. Stent-assisted balloon-induced intimal disruption and relamination in aortic dissection repair: the STABILISE concept. J Thorac Cardiovasc Surg. 2014;147:1240-5.
21. Faure EM, El Batti S, Abou Rjeili M, et al. Mid-term outcomes of stent assisted balloon induced intimal disruption and Relamination in aortic dissection repair (STABILISE) in acute type B aortic dissection. Eur J Vasc Endovasc Surg. 2018;56:209-15.

22. Faure EM, El Batti S, Abou Rjeili M, et al. Stent-assisted, balloon-induced intimal disruption and relamination of aortic dissection in patients with Marfan syndrome: midterm outcomes and aortic remodeling. J Thorac Cardiovasc Surg. 2018;156:1787-93.

23. Kölbel T, Carpenter SW, Lohrenz C, et al. Addressing persistent false lumen flow in chronic aortic dissection: the knickerbocker technique. J Endovasc Ther. 2014:21:117-22.

24. Donas KP, Torsello GB, Piccoli G, et al. The PROTAGORAS study to evaluate the performance of the Endurant stent graft for patients with pararenal pathologic processes treated by the chimney/snorkel endovascular technique. J Vasc Surg. 2016;63:1-7.

25. Donas KP, Lee JT, Lachat M, et al. Collected world experience about the performance of the snorkel/chimney endovascular technique in the treatment of complex aortic pathologies: the PERICLES registry. Ann Surg. 2015:262:546-53 discussion 552-3.

26. Liu J, Li Z, Feng J, et al. Total endovascular repair with parallel stent-grafts for Postdissection Thoracoabdominal aneurysm after prior proximal repair. J Endovasc Ther. 2019;26:668-75.

27. Werlin EC, Kaushik S, Gasper WJ, et al. Multibranched endovascular aortic aneurysm repair in patients with and without chronic aortic dissections. J Vasc Surg. 2019;70:1419-26.

28. Juszczak MT, Murray A, Koutsoumpelis A, et al. Elective fenestrated and branched endovascular Thoraco-abdominal aortic repair with Supracoeliac sealing zones and without prophylactic cerebrospinal fluid drainage: early and medium-term outcomes. Eur J Vasc Endovasc Surg. 2019;57:639-48.

29. Verhoeven EL, Katsargyris A, Bekkema F, et al. Editor's choice-ten-year experience with endovascular repair of Thoracoabdominal aortic aneurysms: results from 166 consecutive patients. Eur J Vasc Endovasc Surg. 2015:49: 524-31

30. Chini J, Mendes BC, Tenorio ER, et al. Preloaded catheters and guide-wire systems to facilitate catheterization during fenestrated and branched endovascular aortic repair. Cardiovasc Intervent Radiol. 2019:42:1678-86.

31. Katsargyris A, Marques de Marino P, Mufty $H$, et al. Early experience with the use of inner branches in endovascular repair of complex abdominal and Thoraco-abdominal aortic aneurysms. Eur J Vasc Endovasc Surg. 2018;55: 640-6.

32. Athanasiou LS, Nezami FR, Edelman ER. Hemodynamic consequences of a multilayer flow modulator in aortic dissection. Med Biol Eng Comput. 2019: 57:1861-74.

33. Sultan S, Kavanagh EP, Stefanov F, et al. Endovascular management of chronic symptomatic aortic dissection with the streamliner multilayer flow modulator: twelve-month outcomes from the global registry. J Vasc Surg. 2017:65:940-50.

34. Zhang Y, Lu Q, Pei Y, et al. Total endovascular repair of thoracoabdominal aortic aneurysms with non-customized stent grafts. Ann Thorac Surg. 2014; 98:1606-12

35. Loubert MC, van der Hulst VP, De Vries $C$, et al. How to exclude the dilated false lumen in patients after a type B aortic dissection? The cork in the bottleneck. J Endovasc Ther. 2003;10:244-8.

36. Hofferberth SC, Nixon IK, Mossop PJ. Aortic false lumen thrombosis induction by embolotherapy (AFTER) following endovascular repair of aortic dissection. J Endovasc Ther. 2012;19:538-45.

37. Roselli EE, Idrees J, Reside J, et al. Use of covered stent devices for false lumen embolization in chronic dissection: a novel approach. Ann Thorac Surg. 2014;98:737-9

38. Idrees J, Roselli EE, Shafii S, et al. Outcomes after false lumen embolization with covered stent devices in chronic dissection. J Vasc Surg. 2014;60:150713.

39. Kim $\mathrm{TH}$, Song $\mathrm{SW}$, Lee $\mathrm{KH}$, et al. The effect of false lumen procedures during thoracic endovascular aortic repair in patients with chronic DeBakey type IIIB dissections. J Vasc Surg. 2018;68:976-84.

40. Kölbel T, Lohrenz C, Kieback A, et al. Distal false lumen occlusion in aortic dissection with a homemade extra-large vascular plug: the candy-plug technique. J Endovasc Ther. 2013:20:484-9.

41. Rohlffs F, Tsilimparis N, Fiorucci B, et al. The candy-plug technique: technical aspects and early results of a new endovascular method for false lumen occlusion in chronic aortic dissection. J Endovasc Ther. 2017;24:549-55. 
42. Eleshra A, Kölbel T, Tsilimparis N, et al. Candy-plug generation II for false lumen occlusion in chronic aortic dissection: feasibility and early results. J Endovasc Ther. 2019;26:782-6.

43. Wu IH, Chan CY, Luo CM, et al. Modified candy-plug device for aneurysmal false lumen occlusion in chronic type B aortic dissection. J Thorac Cardiovasc Surg. 2018;155:1970-2.

44. Marone EM, Leopardi M, Bertoglio L, et al. Original Off-Label Endovascular Solution to Occlude False Lumen Rupture in Chronic Type B Aortic Dissection. Ann Vasc Surg. 2017:40:299.e1-5.

45. Bertoglio L, Marone EM, Civilini E, et al. Branched stent-grafts deployed in the true and false lumen to exclude a post dissecting thoracoabdominal aneurysm. J Cardiovasc Surg. 2016;57:646-52.

46. Jia S, Zhang H, Sun G, et al. Endovascular Retrograde Reconstruction of the Left Renal Artery through the False Lumen of a Postdissection

Thoracoabdominal Aortic Aneurysm-A Case Report. Ann Vasc Surg. 2019;55: 307.e5-307.e11.

\section{Publisher's Note}

Springer Nature remains neutral with regard to jurisdictional claims in published maps and institutional affiliations.

Ready to submit your research? Choose BMC and benefit from:

- fast, convenient online submission

- thorough peer review by experienced researchers in your field

- rapid publication on acceptance

- support for research data, including large and complex data types

- gold Open Access which fosters wider collaboration and increased citations

- maximum visibility for your research: over $100 \mathrm{M}$ website views per year

At BMC, research is always in progress.

Learn more biomedcentral.com/submissions 